\title{
Liposuction Reduction Alone Versus Inferior Pedicle Mammoplasty in Young Females: A Comparative Study
}

\author{
MOHAMED ALI NASR, M.D.; AYMAN FIKRY MEHANNA, M.D. and \\ MAHFOUZ SHEHATA IBRAHIM, M.D., M.R.C.S. \\ The Department of General Surgery, Plastic Surgery Unit, Faculty of Medicine, Zagazig University, Egypt
}

\begin{abstract}
Background: Breast reduction for macromastia represents one of the common aesthetic surgeries. The currently available methods include surgical reduction and/or liposuction. The most commonly performed surgical technique is the inferior pedicle.

Aim: This prospective study aimed to compare the results of surgical reduction by inferior pedicle versus liposuction alone.

Patients and Methods: Between January 2015 and November 2017 fifty two patients were undergone breast reduction by either liposuction alone in 26 patients (group A), Or inferior pedicle technique in the other 26 patients (group B). The patient's demographics, operative notes, hospital stays, reduction in size and volume, postoperative complications and patient's satisfaction were recorded and statistically analyzed.

Results: The operative time, hospital stay, the postoperative complication rate was significantly lower in group A, while the reduction in size and volume was significantly higher in group B. Patient's satisfaction noted to be higher in group A. Significant high rates of complications were observed in inferior pedicle reduction. Regarding patient's satisfaction based on our finding that instead of liposuction reduction alone did not achieve a great reduction in size but patients in this group presenting higher satisfaction rate than the inferior pedicle group due to absence of visible scar.

Conclusion: Based on the finding in this study liposuction breast reduction alone is recommended as first option for breast reduction of medium and even large sized breasts with good skin quality especially for unmarried young females. The inferior pedicle technique might be chosen for reduction of giant breasts.
\end{abstract}

Key Words: Liposuction reduction - Inferior pedicle - Mammoplasty.

\section{INTRODUCTION}

Macromastia is a condition representing a psychological, aesthetic and also somatic complaint in the form of pain in the neck, back, shoulder and bra strap groove, inframammary intertrigo, breathing and sleeping problems and upper extremities numbness [1-3]. Breast reduction for releiving of those symptoms is one of the most common aesthetic surgeries done in US [4]. The currently available methods for breast reconstruction are liposuction and pedicle techniques [5]. Inferior pedicle which was originally described by Riebeiro, Courtiss, and Goldwyn and Robbins had been perhaps the most commonly performed technique in United States [6-8].

Being a surgical procedure the inferior pedicle technique is not without complications $[\mathbf{4 , 9 , 1 0 ]}$. Breast liposuction was first practiced in 1991, it has become a promising method for breast reduction with low morbidities [11].

This study aimed at subjective and objective comparison of liposuction breast reduction versus inferior pedicle mammoplasty being the most currently performed methods for breast reduction.

\section{PATIENTS AND METHODS}

From January 2015 to November 2017 random sample of fifty two patients having macromastia were included in this study. We exclude patients more than 30 years old, those with poor skin quality and those with family history of cancer breast. This study was conducted in plastic surgery unit, general surgery department, Zagazig University, Egypt. Patient's details are summarized in Table (1). Twenty six patients representing odd numbers were operated up on by liposuction alone and described as group A. Twenty six patients represented the even numbers were operated by inferior pedicle reduction and described as group B. All patients were consented to the procedure after it has been approved by the university committee. All preoperative routine investigations including mammography were done for all patients. Patient's records were interpreted with regard to patient's ages, body mass indices (MBI), operative times, 
reduction in sizes (which is known from reduction in sternal notch to nipple distance), amount excised in grams (in liposuction $100 \mathrm{ml}$ aspirated fat is considered equal to 80 grams), relief of preoperative complaint, hospital stays and postoperative complications. Patient's satisfaction was assessed according to Elder et al., 2005 scoring system [12]. All data were presented and statistically analyzed using two sample $t$-test of SPSS version 16 .

Group A surgical technique (Figs. 1-4): In this study we used the technique of Moskovitz and Baxt, 2004 [13] with modifications of using general anaesthesia for all cases and using cannulas numbers 3.7 and 4.6 only. We also used two stabs (one lateral end of inframammary fold while the other just above the breast tissue in the lateral axillary fold) to infiltrate the tumescent solution and to aspirate the fat which were then closed by inverted dermal sutures using poly-glycolic acid 5/0. Post operatively, all patients were dressed in elastic garments which continued for 2 months.

Group B surgical technique (Figs. 4-8): The same as described by Mandrekas et al., 1996 [14] with some modifications of; areola size was only $4 \mathrm{~cm}$ and the suction drains were kept till the amount becomes less than $25 \mathrm{ml}$ serous fluid over 24 hours. Antibiotics were given during induction of anesthesia. Thrombo-prophylaxis was started 12 hours before surgery and then continued for 2 days postsurgery. Small triangles of $0.5 \mathrm{~cm}$ height were left at the center point of the pedicle which were then either kept or removed according to tension at $\mathrm{T}$ shaped junction line during closure.

\section{RESULTS}

All patients of both groups were followed up with average 12 months (range from 6 to 33 months). Table (1) and Fig. (9) illustrate the differences in the age, BMI, operative time, hospital stay, post-operative reduction in size, amount excised or suctioned in grams and relieve of preoperative patient's complain between both groups. Mammography was done at 6 months then after one year in case of liposuction revealed dense glandular element and or scarring in dermal areas which could easily distinguish from malignancy. The mean operative time, hospital stay was significantly low in group A than group B. The mean reduction in breast size manifested by sternal notch to nipple distance and the average amount of excised or suctioned tissue was significantly high in group B than group A (Table 1 and Fig 9).

Most patients of both groups experienced subjective relieve of their preoperative complaint.
The overall complication rate was significantly higher in group B than group A $(p<0.05)$. The percentage of post-operative complication rates (haematoma, loss of nipple and areola sensation, wound complications) was higher in group B than group A. Nipple necrosis, fat necrosis and seromas were comparable in both groups (Table 2).

Patients satisfaction was higher in group A than group B $(92.3 \%$ versus $80.7 \%)$. The most prevalent items of satisfaction are the symmetry and the sensation of nipple and areola while the most prevalent item of dissatisfaction was the post-operative scar. Surprisingly in this study the reduction in size was not a leading item for patient's satisfaction (Table 3, Fig. 10).

Table (1): Demographics, operative time, size, excised tissues, hospital stay and relieve of preoperative complaints.

\begin{tabular}{|c|c|c|c|}
\hline & Group A & Group B & $p^{*}$ \\
\hline Age & $23.69 \pm 11.4$ & $26 \pm 9.9$ & 0.2 \\
\hline Single unmarried & 28 & 24 & \\
\hline $\mathrm{BMI}$ & $27.58 \pm 1.7$ & $28.31 \pm 2$ & 0.3 \\
\hline $\begin{array}{l}\text { Operative time } \\
\text { (minutes) }\end{array}$ & $93.65 \pm 17.2$ & $156 \pm 17.15$ & $0.000^{*}$ \\
\hline $\begin{array}{l}\text { Post-operative Sternal } \\
\text { notch to nipple }(\mathrm{cm})\end{array}$ & $14.5 \pm 1.3$ & $12.75 \pm 2.14$ & $0.000^{*}$ \\
\hline $\begin{array}{l}\text { Amount suctioned or } \\
\text { excised (gm) }\end{array}$ & $639 \pm 201$ & $1265 \pm 447$ & $0.000^{*}$ \\
\hline Hospital stay (days) & $1.1 \pm 0.4$ & $5.69 \pm 1.2$ & $0.000^{*}$ \\
\hline $\begin{array}{l}\text { Relieve of preoperative } \\
\text { complaint }\end{array}$ & $92 \pm 21$ & $85 \pm 35$ & 0.39 \\
\hline
\end{tabular}

Table (2): Postoperative complications.

\begin{tabular}{llll}
\hline Item & $\begin{array}{l}\text { Group B } \\
(\text { num/\%) }\end{array}$ & $\begin{array}{l}\text { Group A } \\
(\text { num/\%) }\end{array}$ & $p^{*}$ \\
\hline Haematoma & $0 / 26$ & $1 / 26(3.8)$ & 0.32 \\
Seroma & $1 / 26(3.8)$ & $2 / 26(7.7)$ & 0.56 \\
$\begin{array}{l}\text { Fat necrosis } \\
\text { Nipple necrosis }\end{array}$ & $1 / 26(3.8)$ & $1 / 26(3.8)$ & 0.54 \\
$\begin{array}{l}\text { Loss of nipple and } \\
\text { areola sensation }\end{array}$ & $0 / 26$ & $3 / 26(11.6)$ & 0.07 \\
$\begin{array}{l}\text { Wound complications } \\
\text { Total }\end{array}$ & $0 / 26$ & $3 / 26(11.6)$ & 0.07 \\
\hline
\end{tabular}

Table (3): Patient's satisfaction after 6 months.

\begin{tabular}{lll}
\hline & Group B & Group A \\
\hline Very satisfied & $17(65.3 \%)$ & $13(50 \%)$ \\
Satisfied & $7(27 \%)$ & $8(30.7 \%)$ \\
Unsatisfied & $2(7.7 \%)$ & $5(19.3 \%)$ \\
\hline
\end{tabular}




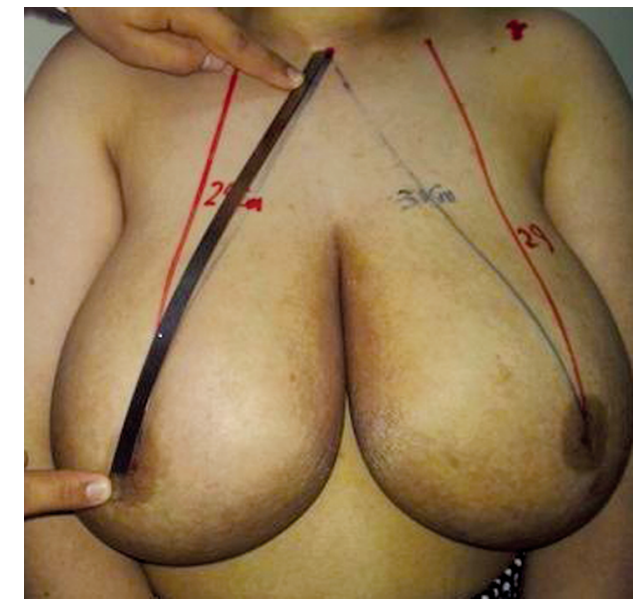

Fig. (1A): Pre-liposuction of breast (case 1) with measurements.

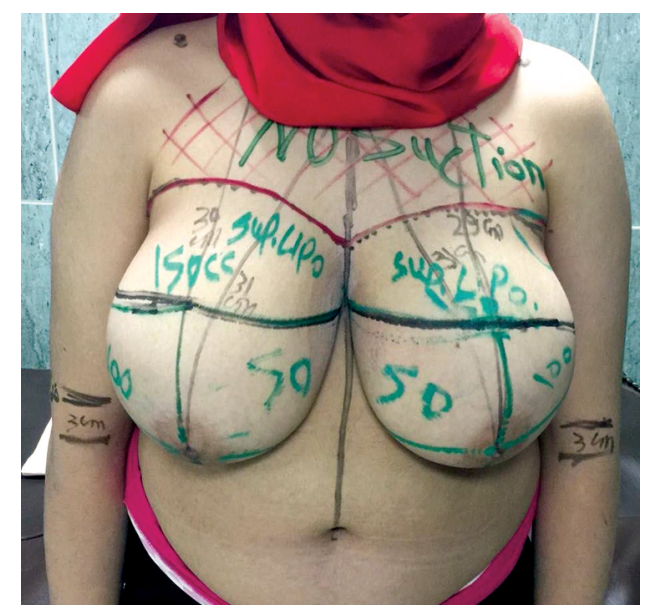

Fig. (2): Pre-liposuction photo (case 2).

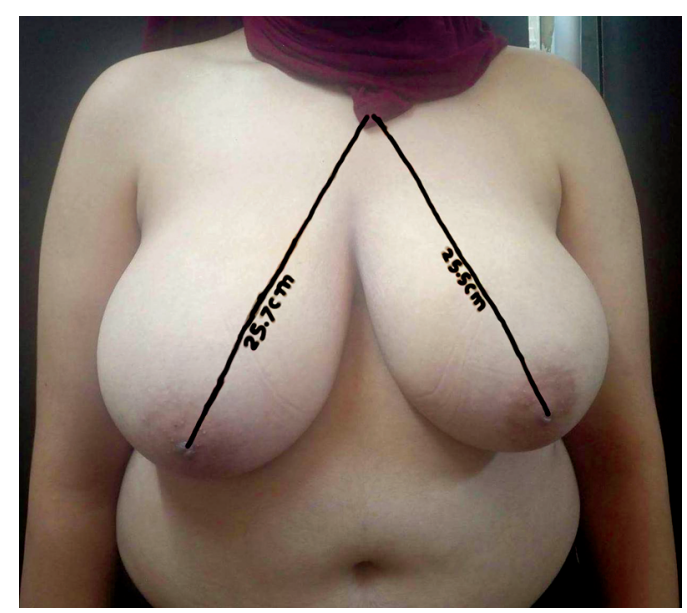

Fig. (4): Post-liposuction photo (case 2).

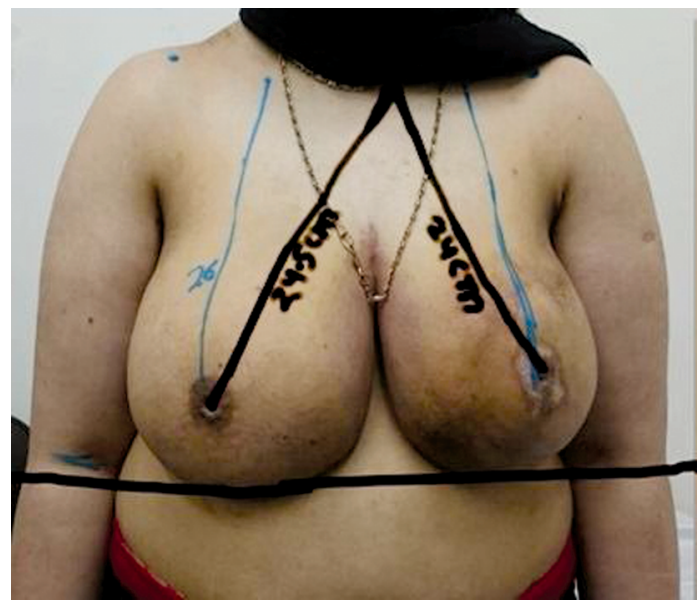

Fig. (1B): Post-liposuction of breast (case 1) with measurements.

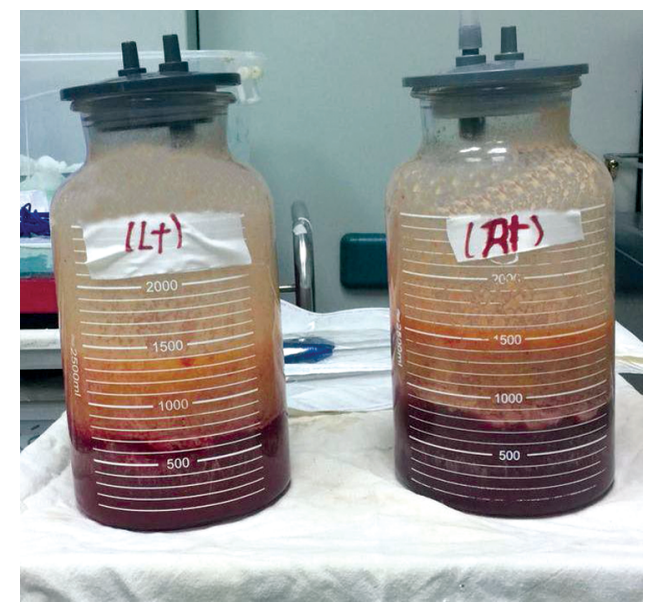

Fig. (3): lipoaspirate (case 2).

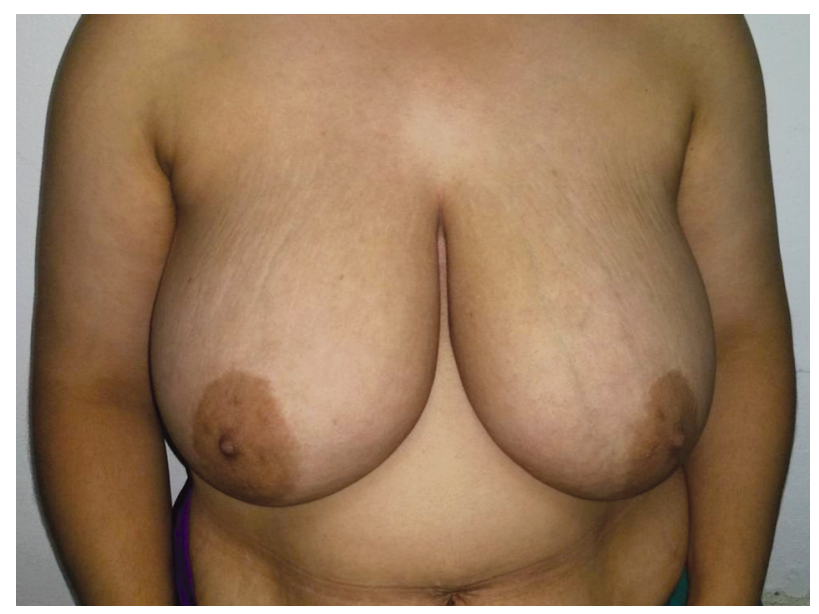

Fig. (5): Pre-op. photo (case 3). 


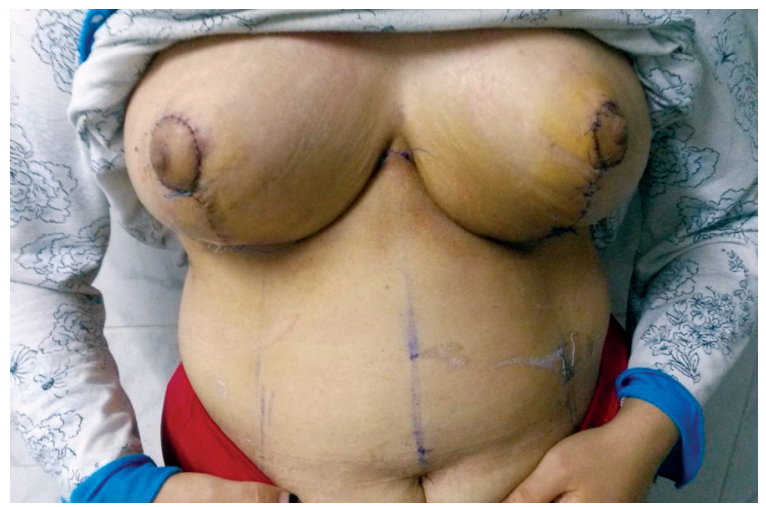

Fig. (6): Post-op. photo (case 3).

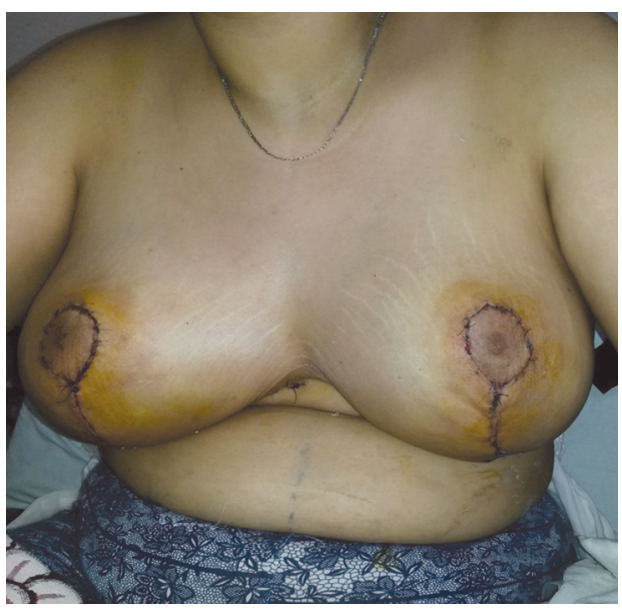

Fig. (8): Post-op. photo (case 4).

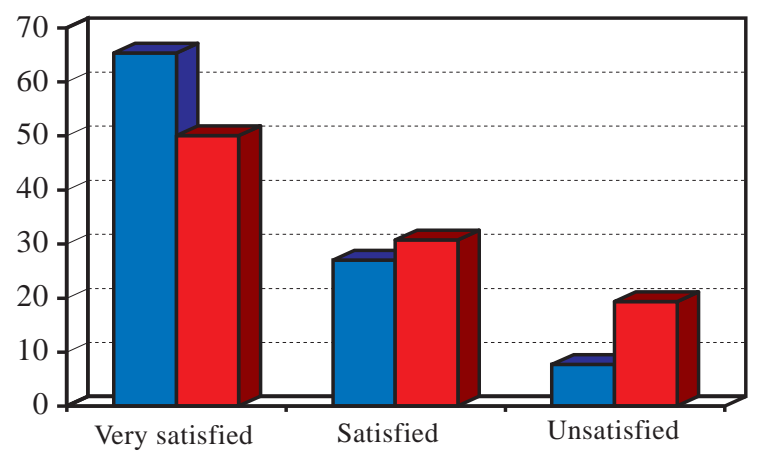

Group A $\square$ Group B

Fig. (10): Patient's satisfaction after 6 months.

\section{DISCUSSION}

Macromastia is not only a psychological and aesthetic troublesome but also somatic complaint for women [1-3].

Currently available methods for breast reduction are liposuction and/or surgical pedicle techniques

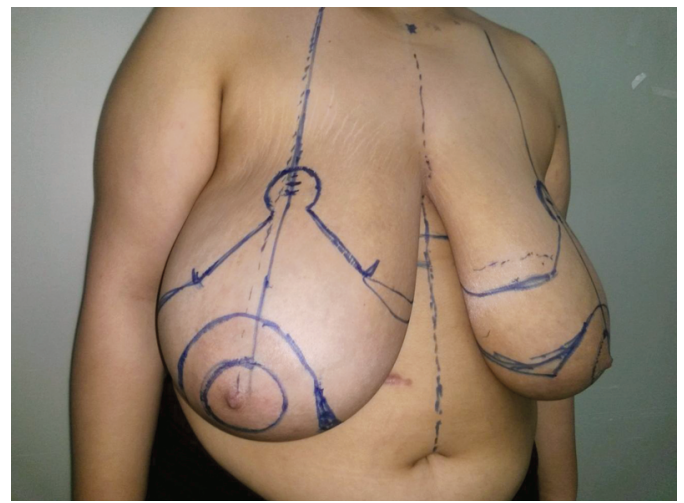

Fig. (7): Pre-op. photo (case 4)

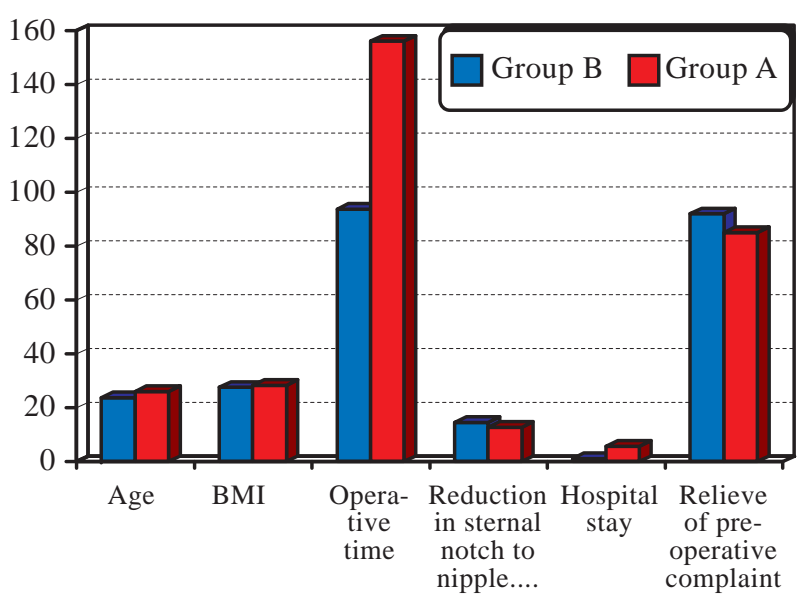

Fig. (9): Demographics, operative time, size, excised tissues, hospital stay and relieve of preoperative complaints.

[5]. All methods are aimed to alleviate the symptoms and to preserve normal breast shape, contour and sensible nipple and areola without neglecting the oncological aspect [15-16].

This prospective study was conducted on 52 patients who divided randomly into two equal groups aiming to compare the most commonly performed procedures for breast reduction.

The mean operative time in liposuction breast reduction alone $(93.65 \pm 17.2 \mathrm{~min})$ was statistically shorter than the inferior pedicle group (156 \pm $17.15 \mathrm{~min}$ ) which means shorter anesthesia time with fewer hazards for the patient.

Other series reported an average operative time of $57 \mathrm{~min}(40-90 \mathrm{~min})$ and $71 \mathrm{~min}(45-130 \mathrm{~min})$ for liposuction reduction respectively [5-17] which is lower than reported by our series due to the learning curve which was low early then improved afterwards while that for inferior pedicle is $120 \mathrm{~min}$ $(125-279 \mathrm{~min}$ and $151.3 \mathrm{~min} \pm 58.9$ which nearly similar to our results $[\mathbf{1 3 , 1 8}]$. 
Both techniques were noted to be comparable in relieve of patient's preoperative somatic complaint and this also reported by multiple previous series [5,19-22].

In this study the mean volume loss per breast after liposuction reduction is significantly lower than the loss by inferior pedicle $(639.2 \mathrm{gm}$ versus $1265.7 \mathrm{gm})$. The reduction in size as noted by the mean reduction in sternal notch to nipple distance is also significantly low in liposuction reduction group $(4.5 \mathrm{~cm}$ versus $12.75 \mathrm{~cm})$.

In a study done by Moskovitz et al., 2007 on liposuction reduction the mean reduction in sternal notch to nipple distance was $4 \mathrm{~cm}$ and average volume loss was 1 liter [19]. Another study done by Mellul et al., 2006 on liposuction reduction the average volume loss was $712.96 \mathrm{cc}$ which equals $570 \mathrm{gm}$ and an average reduction in sternal notch to nipple distance was $2.59 \mathrm{~cm}$ [11]. Other studies reported reduction of $542 \mathrm{gm}$ and $850 \mathrm{gm}$ and mean reduction of sternal notch to nipple distance of $6 \mathrm{~cm}[\mathbf{2 3 , 2 4 ]}$. So results of our study regarding reduction of volume and sternal notch to nipple distance in liposuction group fail in between other series.

Other studies on inferior pedicle mammoplasty reported mean volume losses of $982 \mathrm{gm}$ (average 185 to $1930 \mathrm{gm}$ ), $525 \mathrm{gm}$ (average 400 to $700 \mathrm{gm}$ ) and $1.1 \mathrm{~kg}$ (average 440 to $2500 \mathrm{gm}$ ) $[\mathbf{1 7 , 2 5 , 2 6 ]}$ which are less than reported in our study and this may explained by large sizes of breasts seen in our community.

Nipple and areola sensation was not affected in liposuction reduction group which was also noticed by other series $[\mathbf{1 3}, \mathbf{1 6}, \mathbf{1 9 . 2 1}]$.

Three cases $(11.6 \%)$ developed loss of their sensation in inferior pedicle group which is similar to that reported by other series $13 \%$ and $10 \%$ $[27,283]$.

The overall complication rate was significantly lower in liposuction group than inferior pedicle group (11.6\% versus $46.2 \%)$.

Complication rate of liposuction group fail in the center of that reported by other series; $1.7 \%$, $20 \%, 33 \%$ and $34 \%[\mathbf{5 , 2 2 , 2 9 , 3 0 ]}$.

The complication rate of inferior pedicle group is nearly similar to that reported in other series $47 \%$ and $50 \%[4,31]$ with the most common item is the wound complications.

Patient's satisfaction by liposuction reduction is higher than in inferior pedicle especialy in unmarried single female who seek for scarless reduction $(92.3 \%$ versus $80 \%$ of patients whose ranged from satisfied to very satisfy).

Our results regarding patient's satisfaction by liposuction breast reduction are nearly equal to study done by Moskovitz et al., 2004 who reported $91 \%$ of patients ranged from very satisfied to satisfied while $9 \%$ was unsatisfied and Mellul et al., 2006 who reported $93 \%$ satisfaction rate $[\mathbf{5 , 1 1 ]}$.

In a study done by Makboul et al., 2017 on inferior pedicle mammoplasty $73.3 \%$ of patients was ranged from very satisfied to satisfied while $27 \%$ was unsatisfied and Ramon et al., 2000 reported $75 \%$ of patients was satisfied, while $25 \%$ was unsatisfied which nearly similar to our results $[32,33]$.

In this study the most common item regarding patient's satisfaction is relieve of preoperative somatic complaint while that for dissatisfaction is the postoperative scar. Many series reported that the relieve of preoperative complaint overwhelms the cosmetic concerns and the postoperative scaring is the most frequent cause of dissatisfaction $[25,31,34]$. Others reported that reduction in size is the leading item of patient's satisfaction which was not the case in our study $[\mathbf{5 , 1 1}]$.

\section{Conclusion:}

A high rate of complications was observed in inferior pedicle mammoplasty. Regarding patient's satisfaction and based on our finding that instead of liposuction reduction alone did not achieve a great reduction in size and volume but patients in this group presenting higher satisfaction rate than the other group due to absence of visible scars especially in unmarried female with good skin quality.

Based on the finding in this study liposuction breast reduction alone is recommended as first option for breast reduction of medium sized breasts with good skin quality. The inferior pedicle technique might be chosen for reduction of large to giant breasts or for patients who are unsatesfied with breast liposuction.

\section{REFERENCES}

1- Noone R.B.: An evidence-based approach to reduction mammoplasty. Plast. Reconstr. Surg., 126: 2171-2176, 2010.

2- Eggert E., Schuss R. and Edsander-Nord A.: Clinical outcome, quality of life, patients' satisfaction, and aesthetic results, after reduction mammoplasty. Scand. J. Plast. Reconstr. Surg. Hand Surg., 43: 201-206, 2009. 
3- Spector J.A., Singh S.P., Karp N.S. Outcomes after breast reduction: Does size really matter? Annal. Plast. Surg. 60: 505-509, 2008.

4- Ogunleye A.A., Leroux O., Morrison N. et al.: Complications after Reduction Mammoplasty A Comparison of Wise Pattern / Inferior Pedicle and Vertical Scar / Superomedial Pedicle. Annal. Plast. Surg., 79: 13-16, 2017.

5- Moskovitz M.J., Muskin E. and Baxt S.A.: Outcome Study in Liposuction Breast Reduction. Last. Reconst. Surg., 114: 56-60, 2004.

6- Ribeiro L.: A new technique for reduction mammoplasty. Plast. Reconstr. Surg., 55: 330-4, 1975.

7- Courtiss E.H. and Goldwyn R.J.: Reduction mammoplasty by the inferior pedicle technique. Plast. Reconstr. Surg., 59: 500-7, 1977.

8- Robbins T.H.: A reduction mammoplasty with the areolanipple based on an inferior dermal pedicle. Plast. Reconstr. Surg., 59: 64-7, 1977.

9- Mandrekas A.D., Zambacos G.J., Anastasopoulos A., et al.: Reduction mammaplasty with the inferior pedicle technique: Early and late complications in 371 patients. Br. J. Plast. Surg., 49: 442, 1996.

10- Hamdi M., Greuse M. and Webster M.H., et al,.: A prospective quantitative comparison of breast sensation after superior and inferior pedicle mammaplasty. Br. J. Plast. Surg., 54: 39-42, 1999.

11- Mellul S.D., Dryden R.M., Remigio D.J., et al.: Breast Reduction Performed by Liposuction. Dermatol. Surg., 32: 1124-1133, 2006.

12- Elder E.E., Brandberg Y., Bjorklund T., et al.: Quality of life and patient satisfaction in breast cancer patients after immediate breast reconstruction: A prospective study. Breast, 14: 201-8, 2005.

13- Moskovitz M.J. and Baxt S.A.: Breast Reduction Using Liposuction Alone. Semin. Plast. Surg., 18: 225-229, 2004.

14- Mandrekas A.D., Zambacos G.J., Anastasopoulos A., et al.: Reduction mammoplasty with the inferior pedicle technique: Early and late complications in 371 patients. Br. J. Plast. Surg., 49: 442-446, 1996.

15- Price M.F., Massey B., Rumbolo P.M., et al.: Liposuction as an Adjunct Procedure in Reduction Mammoplasty. Annal. Plast. Surg., 47: 115-118, 2001.

16- Matarasso A.: Breast reduction by suction mammoplasty Oper. Tech. Plast. Reconstr. Surg., 6: 136-140, 1999.

17- DeFazio M.V., Fan K.L., Avashia Y.J., et al.: Inferior pedicle breast reduction: A retrospective review of technical modifications influencing patient safety, operative efficiency, and postoperative outcomes. Am. J. Surg., 204: 7-14, 2012.

18- James A. and Verheyden C.: A Retrospective Study Comparing Patient Outcomes of Wise Pattern-Inferior Pedicle and Vertical Pattern-Medial Pedicle Reduction Mammoplasty. Annal. Plast. Surg., 67: 481-483, 2011.
19- Moskovitz M.J., Baxt S.A., Jain A.K. et al.: Liposuction Breast Reduction: A Prospective Trial in African American Women. Plast. Reconstr. Surg., 119: 718-726, 2007.

20- Collins E.D., Kerrigan C.L., Kim M., et al.: The effectiveness of surgical and nonsurgical interventions in relieving the symptoms of macromastia. Plast. Reconstr. Surg., 109: 1556-1566, 2002.

21- Matarasso A.: Suction mammoplasty: The use of suction lipectomy to reduce large breasts. Plast. Reconstr. Surg., 105: 2604, 2000 .

22- Mizgala C.L. and MacKenzie K.M.: Breast reduction outcome study. Ann. Plast. Surg., 44: 125-133, 2000.

23- Habbema L.: Breast Reduction Using Liposuction with Tumescent Local Anesthesia and Powered Cannulas. Dermatol. Surg., 35: 41-52, 2009.

24- Gray L.N.: Update on experience with liposuction breast reduction. Plast. Reconstr. Surg., 108: 1006-1010, 2001.

25- Elebiler O.C., Nmez A.S., Erdim M., et al.: Patients' and Surgeons' Perspectives on the Scar Components after Inferior Pedicle Breast Reduction Surgery. Plast. Reconstr. Surg., 116: 459-464, 2004.

26- Mofid M.M., Dellon A.L., Elias A., et al.: Quantitation of breast sensibility following reduction mammoplasty: A comparison of inferior and medial pedicle techniques. Plast. Reconstr. Surg., 109: 2283-2288, 2002.

27- Akyurek M. and Chappell A.G.: Short-Scar Mammaplasty in Severe Macromastia. Ann. Plast. Surg., 77: 609-614, 2016.

28- Ahmed O.A. and Kolhe P.S.: Comparison of nipple and areolar sensation after breast reduction by free nipple graft and inferior pedicle. Br. J. Plast. Surg., 53: 126-129, 2000.

29- Schnur P.L., Shnur D.P., Petty P.M., et al.: Reduction mammoplasty: An outcome study. Plast. Reconstr. Surg., 100: 875-883, 1997.

30- Brown A.P., Hill C. and Khan K.: Outcome study of reduction mammaplasty: A patient's perspective. Br. J. Plast. Surg., 53: 584, 2000.

31- Davis G.M., Ringler S.L., Short K., et al.: Reduction mammoplasty: Long-term efficacy, morbidity, and patient satisfaction. Plast. Reconstr. Surg., 96: 1106-10, 1995.

32- Makboul M., Abdelhamid M. and Al-Attar G.: Long Term Follow-up and Patient Satisfaction after Reduction Mammoplasty: Super medial versus Inferior Pedicle. World. J. Plast. Surg., 6: 82-87, 2017.

33- Ramon Y., Sharony Z., Moscona R.A., et al.: Evaluation and Comparison of Aesthetic Results and Patient Satisfaction with Bilateral Breast Reduction Using the Inferior Pedicle and McKissock's Vertical Bipedicle Dermal Flap Techniques. Plast Reconstr. Surg., 106: 289-295, 2000.

34- Hammond D.C. and Loffredo M.: Breast Reduction. Plast. Reconstr. Surg., 129: 829-839, 2012. 